\title{
The game-changing potential of digitalization for sustainability: possibilities, perils, and pathways
}

\author{
Peter Seele ${ }^{1}$ Irina Lock ${ }^{2}$
}

Published online: 15 February 2017

(C) Springer Japan 2017

When in 2015, 193 countries agreed on 17 sustainable development goals, the nations' delegates signed a challenging agenda aimed to render this planet livable for future generations within the next 15 years. This process has just begun and implementation and dialogue with different stakeholders is required to bring the SDG to live. This is true, particularly given the past steps to strive for sustainability, which have not yet led to groundbreaking levels of achieving more sustainability (or less unsustainability). Despite many efforts in developing and developed countries, none of the member states of the United Nations has achieved all goals yet (GeSI 2016), so the call for intensifying engagement and transforming societies remains open. This is where Big Data and Digitalization comes in: Digital technologies in the form of e-health services, robotics, or emission reduction solutions could help individuals, organizations, and nations achieve a more sustainable planet in light of the sustainable development goals. Given the stagnation of sustainable development, the overall "sustainability gap" (Lubin and Esty 2014) continues to be a major issue, as the overconsumption of natural resources and its harmful consequences threaten the basis of our existence and that of future generations (WCED 1987).

Parallel to this development stands the increasing speed and spread of digital technology in all areas of life. Information and communication (ICT) technology constitute our new "digital age" (Schmidt and Cohen 2013), encompassing a richness of soft- and hardware and linked processes. Analyses of genetic sequences, personal health data, phone

Peter Seele

peter.seele@usi.ch

Università della Svizzera italiana, Lugano, Switzerland

2 University of Amsterdam, Amsterdam, Netherlands records, social media profiles, and many more (Boyd and Crawford 2012) have altered the way humans interact with each other and with their natural environment. Digital technology, as in the example of Big Data, offers new possibilities and pathways of how to shape the future and research (Shah et al. 2015), for instance, through the "information civilization" brought about by monopolistic structures in the corporate sphere (Zuboff 2015). Algorithmic capacities allow for data processing and analysis that open up unseen predictive capabilities, and thus a "time-ontological shift" (Seele 2016a). Digitalization has (positively as well as negatively) incalculable potential to help achieve sustainability of the planetary and human system, or at least help reduce the negative impact of people. ICT and Big Data can help promote sustainability (Gijzen 2013; Hampton et al. 2013), because the societal complexity of the planetary nervous system is strongly connected and these systems may lead to cascading effects that increase vulnerability (Helbing 2012). Via a big data-driven "transnational sustainability agency" (Seele 2016b) or a digital "global participatory platform", for instance, digitalization can help increase (strong) sustainability in the environmental, social and economic spheres (Helbing 2012). Hence, digitalization bears consequences for transparency and accountability that open up entirely new ways to shape, monitor, communicate, and govern sustainability (e.g., Heemsbergen 2016). In conclusion, both megatrends, sustainability and digitalization, impose major transitions on our world and how we picture it.

In this regard, sustainability science is the scientific way of gathering data to analyze pathways towards a (more) sustainable world, by taking into account future generations. Given its transformative nature, sustainability is expected to adapt to the new possibilities and perils of the digital age, or vice versa, digitalization is the driver that 
changes sustainability. Whether and in how far this transformation through digitalization facilitates or impedes the development of a more sustainable world, however, is still unknown. The purpose of this special issue is therefore to shed light on the different possibilities, perils, and pathways the digital revolution can bring for sustainability and sustainability science and intends to address the overall question: In what ways is digitalization a game changer for sustainability?

The papers in this special issue deal with the impact of digitalization on sustainability in manifold ways, applying an array of disciplinary, methodological, cultural, and topical perspectives.

Analyzing e-participation of citizens in environmentally sensitive projects through ICTs, He et al. (2016) investigated the potentials of digital communication technology in a Chinese setting. The article "E-participation for environmental sustainability in transitional urban China" applies a mixed methods approach. The authors investigate how ICTs can facilitate e-participation and governance from the citizens' and the governments' perspectives. They provide particularly interesting insight by embedding analysis into the context of the rapidly evolving and changing Chinese economy and a political system that is vulnerable to civil unrest. They conclude that e-participation bears potential in urban China and elsewhere, because it allows effective mobilization of citizens.

Gliedt, Widener, and Hartman's study "Visualizing dynamic capabilities as adaptive capacity for municipal water governance" (2016) is set in the State of Oklahoma, US. It analyzes how local communities have or have not adapted and innovated their water systems to mitigate climate change. With a mixed methods approach using geographic information system technology paired with interviews and observations, the authors present drivers and barriers of the adaptation and innovation of water resource infrastructure. Through digitalization of these data, a "diverging perspective on the historical lack of innovation in the public sector" is provided. From their results the authors conclude that dynamic capabilities influence innovation and adaptation rates directly. Population size, income level, and the educational backgrounds of decision makers relate indirectly to the adaptation and innovation in municipal water governance. The article also outlines implications for public policy beyond the investigated context.

Tabira and Francis's article "Integration and implementation of sustainable ICT-based education in developing countries: low-cost, en masse methodology in Kenya" (Tabira and Francis 2017) looks at the use of ICTs in education in the context of developing countries, more specifically Kenya. Given the lack of basic digital infrastructure and inconsistent electric supplies, this setting is of particular interest yet rarely investigated. The authors studied the effectiveness (in terms of test results) of the use of digital content in school lessons compared to lessons with traditional content. They find that given power outages and other technical malfunctions, teachers were unable to manage the switch between digital lessons and traditional methods of teaching, which resulted in diminished interest and lowered concentration of students. Thus, the sustainable development goal of 'quality education for all' is not necessarily facilitated through ICT-based teaching in developing countries, because of insufficient ICT infrastructures. This deepens rather than bridges the education gap between developed and developing regions instead of facilitating global learning opportunities through the ubiquity of information in the 'digital age'.

Lock and Seele (2016) offer a conceptual account when they outline ten stakeholders of sustainability in the digital age in their article "Theorizing stakeholders of sustainability in the digital age". By taking on a stakeholder theory perspective that originated in management studies, the authors look at sustainability as a normative concept, positioning it as the center of a stakeholder map. The authors operationalize ten stakeholders of sustainability describing the complex interplay between stakeholders focused on their 'stake' in sustainability and their responsibility to contribute to advance, promote, and achieve sustainability in the digital age. Particular interest is given to the gamechanging role of Big Data when structuring the sustainability stakeholders along the three types: Big Data Collectors, Big Data Utilizers, and Big Data Generators. The authors outline that a common vision of all stakeholders involved to engage in the advancement of sustainability and to aim for transformation of the state of affairs is required.

Stürmer, Abu-Tayeh, and Myrach conclude the special issue from a knowledge science perspective, considering the development of a knowledge society and the phenomenon of digitalization. In the article "Digital sustainability: basic conditions for sustainable digital artifacts and their ecosystems" (2016), the authors argue that unlike natural resources, knowledge cannot be depleted but rather increases societal benefit by its use. In their conceptual paper, the authors advance theory by contributing a "floor" model of sustaining digital knowledge and by applying this model to case studies to outline the characteristics of digitally sustainable goods. In conclusion, an agenda for sustainability scholars and innovation academics as well as practitioners such as policy makers is provided.

These five articles from a palette of disciplines with different ontological presuppositions thus provide a window into the world we live in and the diverse approaches that humans apply to counterbalance their very own detrimental impacts on the planetary system. 
This has been a first advance in mapping the megatrends of digitalization and sustainability and in deducing possibilities, perils and pathways from them. Above and beyond this special issue and the thematic papers, some avenues for future research open up in sustainability science with relation to digitalization.

1. The governance of sustainability in a digitalized environment has not been addressed in this special issue, even though it appears to be a central concern for policy makers. Helbing (2012) suggested a digital "global participatory platform" making use of ICT that can help "promote human well-being, increase sustainability, promote fairness, increase resilience and reduce damages and improve opportunities for economic, political, and social participation" (p. 56). Seele (2016b) approached the issue of governance from a philosophical perspective by applying panopticon theory to sustainability in the digital age. However, these approaches have not yet been transferred to practice, which opens further potential for academic inquiry.

2. Sustainable development and base-of-pyramid in the digital age: Although two studies in this special issue focus on a developing countries context, further insights into the potentials and threats of digital technologies for global sustainable development are needed. How can digital technology help achieve the 17 UN Sustainable Development Goals in the 15 years to come? This major question has immediate practical relevance and must therefore be addressed by researchers and policy makers alike.

3. The controversial role of digital surveillance. Digital technology as conceptualized here to promote sustainability comes with enhanced surveillance technologies. Surveillance here is a two-edged sword. On one hand, big data and intelligent algorithmic ways of analyzing these partly structured partly unstructured data come with a degree of detail unrecorded in history. Thus, the precision and technological rigor to obtain data relevant for promoting sustainability is a great chance of doing the right thing right. The papers compiled in this special issue provide evidence for this in different areas. On the other hand, however, digitalization opens horizons of totalitarian-like surveillance limiting or undermining people's and organization's legal rights to privacy. Next to privacy issues, questions of data-misuse and political misuse of surveillance arise. This ambivalent role of digital surveillance remains; further research is needed both for protecting persons and organizations and making the most out of digital data to promote sustainability.
Overall, we may conclude that in leveraging the transformative potential of both sustainability and digitalization we are still right at the beginning on all levels, be it technologically, conceptually, politically, or scientifically.

\section{References}

Boyd D, Crawford K (2012) Critical questions for big data: provocations for a cultural, technological, and scholarly phenomenon. Inf Commun Soc 15(5):662-679

GeSI (2016) \#SystemTransformation. Brussels: Global e-Sustainability Initiative. http://www.systemtransformation-sdg.gesi.org. Accessed 7 Jan 2017

Gijzen H (2013) Development: big data for a sustainable future. Nature 502:38-38

Hampton SE, Strasser CA, Tewksbury JJ, Gram WK, Budden AE, Batcheller AL, Duke CS, Porter JH (2013) Big data and the future of ecology. Front Ecol Environ 11(3):156-162

He G, Boas I, Mol AP, Lu Y (2016). E-participation for environmental sustainability in transitional urban China. Sustain Sci 1-16. doi:10.1007/s11625-016-0403-3

Heemsbergen L (2016) Digital agel from radical transparency to radical disclosure: reconfiguring (in) voluntary transparency through the management of visibilities. Int J Commun 10:138-151

Helbing D (2012) The FuturICT knowledge accelerator towards a more resilient and sustainable future. In: Ball P (ed) Why society is a complex matter. Springer, Berlin, pp 55-60

Lock I, Seele P (2016). Theorizing stakeholders of sustainability in the digital age. Sustain Sci 1-11. doi:10.1007/s11625-016-0404-2

Lubin, D.A. and Esty, D.C. (2014), "Bridging the sustainability gap", MITSloan Management Review, June 2014

Schmidt E, Cohen J (2013) The new digital age. Reshaping the future of people, nations and business. Knopf, New York

Seele P (2016a) Digitally unified reporting: how XBRL-based realtime transparency helps in combining integrated sustainability reporting and performance control. J Cleaner Prod 136:66-77. doi:10.1016/j.jclepro.2016.01.102

Seele P (2016b) Envisioning the digital sustainability panopticon: a thought experiment how big data may help advancing sustainability in the digital age. Sustain Sci 11(5):845-854. doi:10.1007/ s11625-016-0381-5

Shah DV, Cappella JN, Neuman WR (2015) Big data, digital media, and computational social science possibilities and perils.Ann Am Acad Polit Soc Sci 659(1):6-13

Stuermer M, Abu-Tayeh G, Myrach T (2016) Digital sustainability: basic conditions for sustainable digital artifacts and their ecosystems. Sustain Sci 1-16. doi:10.1007/s11625-016-0412-2

Tabira Y, Francis OX (2017) Integration and implementation of sustainable ICT-based education in developing countries: low-cost, en masse methodology in Kenya. Sustain Sci. doi:10.1007/ s11625-017-0422-8

WCED (World Commission on Environment and Development) (1987) Our common future. Aka.'The Brundtland Report\&\#8217

Widener JM, Gliedt TJ, Hartman P (2016). Visualizing dynamic capabilities as adaptive capacity for municipal water governance. Sustain Sci 1-17. doi:10.1007/s11625-016-0408-y

Zuboff S (2015) Big other: surveillance capitalism and the prospects of an information civilization. J Inf Technol 30(1):75-89 